\title{
Beneficios tributarios y su relación con el déficit fiscal en Colombia, durante el período comprendido entre los años 2005 y 2010
}

\author{
Ramiro César Barajas Gómez ${ }^{1}$
}

\begin{abstract}
Resumen
En Colombia el deterioro del déficit fiscal ha venido siendo una constante. A su vez, existe un número importante de tratamientos especiales tales como exenciones, deducciones, descuentos y tarifas diferenciales que distorsionan el sistema tributario y disminuyen los ingresos fiscales de manera significativa, generando una inequidad injustificable en la economía nacional. Un caso especial son las exenciones en las zonas francas con pago en impuesto de renta del $15 \%$ y el descuento del $40 \%$ de descuento en renta por adquisición de activos fijos, entre otros.

El presente trabajo busca demostrar cómo a través de los beneficios tributarios concedidos a algunos contribuyentes instalados en las zonas francas y que pretendían, inicialmente, generar empleo, incentivar la inversión extranjera, y el crecimiento y desarrollo económico, no cumplieron su objetivo y en cambio sí han contribuido a aumentar el déficit fiscal.
\end{abstract}

Palabras clave: impuestos, deuda, déficit fiscal, zonas francas, exenciones, evasión. 


\title{
Fiscal benefits and their relation to fiscal deficit in Colombia during years 2005-201
}

\begin{abstract}
Fiscal decay in Colombia has been a constant. Besides, there is a significant number of special treatments, such as exemptions, deductions, discounts and differential fees that distort the tax system and shrink fiscal revenues significantly, generating an unjustifiable unequality in the country's economy. A special case are exemptions on duty-free zones, which are liable to pay an income tax over $15 \%$ and are covered by a 40 percent discount on income tax when acquiring fixed assets, among others.

This paper aims to show how tax benefits that were granted to some contributors based on duty free zones - originally aiming to generate jobs, encourage foreign investment, and contribute to economic growth and development-, did not accomplish that goal, but rather have contributed to increase fiscal deficit.
\end{abstract}

Key Words: taxes, debt, fiscal deficit, duty free zones, exemptions, tax evasion.

\section{lntroducción}

Expertos como Juan Camilo Restrepo (2009) y Sergio Clavijo señalan las consecuencias que han tenido en el gasto social, especialmente en educación y salud, las exenciones tributarias y los subsidios que se han otorgado a grandes empresas y a las zonas francas. ${ }^{2}$ Sin embargo, el gobierno plantea la necesidad de aumentar el IVA y recurrir al crédito para conseguir los recursos que cubran el déficit fiscal; sin mencionar las alternativas que existen para tal 
fin: aumentar el recaudo tributario impidiendo la evasión y la elusión, bajar o eliminar las exenciones para ofrecer así mayores recursos a la nación y no tener como únicas alternativas la disminución del gasto público o el aumento de los impuestos.

Los fines de las exenciones son, por ejemplo, atraer la inversión extranjera directa o incentivar algún sector de la economía que por algún motivo se vea vulnerado o esté rezagado frente a otros, o incluso estimular la producción de excedentes exportables. Por ese motivo, los incentivos se otorgan en las zonas de fronteras o en los principales puertos donde se ubicaban las zonas francas, por su facilidad para el comercio exterior. Sin embargo, se propicia una particular forma de inequidad al otorgar exenciones tributarias a un pequeño grupo de privilegiados que tienen suficientes recursos para pagar sus obligaciones tributarias correspondientes por ley.

Dicha situación puede llevar a un problema fiscal o al menos a agravarlo, si a ella se suman los ya conocidos problemas de evasión y elusión, que se facilitan por el intrincado sistema tributario que hay en Colombia. Esto quebranta los principios de equidad y solidaridad de la capacidad contributiva que sugiere que quienes tienen más, deben contribuir más al financiamiento estatal, lo cual hace que se aumenten los ingresos para financiar el gasto público.

Está muy extendida la creencia de que un 'buen' sistema tributario debe reunir las siguientes condiciones: 1) Eficiencia económica: no debe interferir en la asignación eficiente de los recursos. 2) Sencillez administrativa: debe ser fácil y relativamente barato de administrar. 3) Flexibilidad: debe ser capaz de responder fácilmente (en algunos casos automáticamente) a los cambios de las circunstancias económicas. 4) Responsabilidad política: debe diseñarse de tal forma que cada individuo pueda averiguar qué está pagando para que el sistema político pueda reflejar con mayor precisión sus preferencias. 5) Justicia: debe ser justo en su manera de tratar a los deferentes individuos (Stiglitz, 1995: 430).

Si se acepta la anterior afirmación, significa que en Colombia es necesaria una revisión del sistema tributario.

Al considerar los incentivos al capital con el objeto de crear trabajo, Todaro escribió en El desarrollo económico en el tercer mundo que:

$\mathrm{Si}$ se suprimiesen estos privilegios especiales y subvenciones al capital de forma que su precio se elevase hasta el verdadero nivel que reflejase su 'escasez', los productores tendrían un incentivo adicional para incrementar la utilización de la oferta abundante de trabajo y disminuiría su utilización del capital, que sería muy escaso. Más aún, los propietarios del capital (tanto material como financiero) no permitirían 
los rendimientos económicos artificialmente elevados de que ahora disfrutan (1985: 209).

En esta investigación se entenderá el déficit fiscal como el valor negativo de la diferencia entre ingresos y los egresos públicos en un período determinado que generalmente es de un año, es decir, cuando el gobierno gasta más de lo que recibe. Se considerarán además las exenciones, como aquellos descuentos tributarios que se conceden a personas jurídicas y naturales y que están autorizadas por la legislación Y tributo finalmente, como aquella cantidad de dinero que las personas jurídicas y naturales deben pagar al Estado para su sostenimiento; estos pueden ser de tres categorías: tasas, impuestos y contribuciones especiales.

\section{Materiales y métodos}

\section{Diseño metodológico}

Se utilizó un diseño analítico, no experimental, cuantitativo. Para la primera parte del estudio que hace referencia a las zonas francas, se utilizó un diseño transeccional que buscó comparar el crecimiento de zonas francas permanentes y especiales tomando como periodo de análisis los años comprendidos entre 2005 y 2010 (Bonilla y Rodríguez, 1997).

En la segunda parte del estudio que hace referencia a los impuestos nacionales, se utilizó un diseño de tipo longitudinal de tendencia que buscó analizar cambios de variables de interés como fueron: (a) exenciones, (b) empleo, (c) inversión, (d) impuestos, (e) importaciones y exportaciones, (f) deuda interna y externa, $(\mathrm{g})$ déficit fiscal, $(\mathrm{h})$ evasión de impuestos, a través del tiempo: años 2005, 2006, 2007, 2008, 2009 y 2010.

Como método de recolección general de datos se empleó la metodología del análisis secundario que utiliza datos ya recabados por entidades gubernamentales como el DANE, la DIAN, el Ministerio de Comercio, el Ministerio de Hacienda y Banco de la República.

Para el desarrollo de la presente investigación en el apartado de zonas francas se usaron los datos del Ministerio de Comercio, en cuanto a cantidad de zonas francas permanentes y especiales, así como solicitudes de las mismas. Datos de la DIAN en cuanto a evolución de zonas francas y datos del Banco de la República en cuanto a compromisos de empleo e inversión.

En el apartado de impuestos nacionales, la información de cada una de las variables analizadas y su fuente se presentan en la siguiente tabla: 
Tabla 1. Entidades fuente de información para cada una de las variables analizadas.

\begin{tabular}{|l|l|}
\hline Variable & Fuente \\
\hline Exenciones & DIAN y Banco de la República \\
\hline Compromisos de empleo & Banco de la República \\
\hline Inversión & Banco de la República \\
\hline Impuestos & DIAN y Banco de la República \\
\hline Importaciones y exportaciones: & DIAN y Banco de la República \\
\hline deuda interna y externa & DIAN y DANE \\
\hline Déficit fiscal & Ministerio de Hacienda \\
\hline Evasión de impuestos & DIAN \\
\hline
\end{tabular}

\section{Muestra y diseño muestral}

Se tomó como muestra el total de la población accesible, es decir, todas las zonas francas en Colombia, a la hora de realizar el análisis secundario bajo la metodología de recolección de datos transeccional. Este análisis tiene como propósito describir variables, y analizar su incidencia e interrelación en un momento dado para compararlo con otro de acuerdo a lo descrito anteriormente (Hernández et al, 2010). Adicionalmente se analizó el Balance Fiscal del Gobierno Nacional Central durante los años 2005, 2006, 2007, 2008, 2009 y 2010.

\section{Resultados}

\section{Grupos de interés}

A partir de 1991, a la par de la apertura económica, comenzó un proceso de privatización y en 1993 se dio un nuevo impulso a las zonas francas con la declaración de las localizadas en Bogotá, Candelaria, Rionegro y Pacífico. En 1996 se creó la del Eje Cafetero y en 2000 la Ciudadela de la Salud en Sopó.

Las zonas francas buscan no solo la atracción de nuevas inversiones y la generación de empleo, sino además incentivar el desarrollo de procesos altamente productivos, competitivos y con un importante componente de innovación tecnológica. 


\section{Ramiro César Barajas Gómez}

Beneficios tributarios y su relación con el déficit fiscal en Colombia durante el período comprendido entre los años 2005 y 2010, artículo producto de la investigación

Tabla 2. Zona francas declaradas antes de la Ley 1004 de 2005.

\begin{tabular}{|l|l|l|l|l|l|l|}
\hline \multicolumn{5}{|c|}{ COMISIÓN INTERSECTORIAL ZONAS FRANCAS- SECRETARIA TÉCNICA } \\
\hline \multicolumn{5}{|c|}{ INFORME ZONAS FRANCAS ANTES DE LEY 1004 } \\
\hline NO & ZONA FRANCA & SECTOR & RESOLUCIÓN & $\begin{array}{l}\text { Fecha } \\
\text { Declaratoria }\end{array}$ & Ciudad & Departamento \\
\hline 1 & Rio negro & Industrial & No & $10 / 02 / 1993$ & Río Negro & Antioquia \\
\hline 2 & Candelaria & Industrial & 94 & $10 / 02 / 1993$ & Cartagena & Bolívar \\
\hline 3 & Bogotá & Industrial & 95 & $06 / 08 / 1993$ & Bogotá & Cundinamarca \\
\hline 4 & Pacifico & Industrial & 934 & $26 / 08 / 1993$ & Palmira & Valle del Cauca \\
\hline 5 & Palmaseca & Industrial & 1035 & $02 / 06 / 1994$ & Palmira & Valle del Cauca \\
\hline 6 & Barranquilla & Industrial & 835 & $20 / 06 / 1994$ & $\begin{array}{l}\text { Barran- } \\
\text { quilla }\end{array}$ & Atlántico \\
\hline 7 & Cartagena & Industrial & 978 & $2 / 06 / 1994$ & Cartagena & Bolívar \\
\hline 8 & Cúcuta & Industrial & 977 & $29 / 06 / 1994$ & Cúcuta & $\begin{array}{l}\text { Norte de San- } \\
\text { tander }\end{array}$ \\
\hline 9 & Santa Marta & Industrial & 1059 & $29 / 06 / 1994$ & $\begin{array}{l}\text { Santa } \\
\text { Marta }\end{array}$ & Magdalena \\
\hline 10 & Eje Cafetero & Industrial & 1060 & $03 / 07 / 1996$ & Armenia & Quindío \\
\hline 11 & Ciudadela Salud & Industrial & 751 & $29 / 02 / 2000$ & Sopó & Cundinamarca \\
\hline & $\begin{array}{l}\text { Fuente. } \\
\text { Mincomercio }\end{array}$ & 217 & RESUMEN & TOTAL & \\
\hline & & & RADAS & 11 & \\
\hline
\end{tabular}

Como puede verse en la Tabla 2, hasta antes de la Ley 1004 de 2005, solo había en Colombia 11 zonas francas declaradas, todas industriales, de las cuales había dos en Bolívar, dos en el Valle del Cauca, dos en Cundinamarca, una en Antioquia, una en Atlántico, una en Norte de Santander, una en el Magdalena y una en Quindío. Sin embargo, debe resaltarse que cuatro se declararon en 1993, cinco en 1994, solo una en 1996 y otra en 2000.

\section{Cambios recientes}

En 2007, con el Decreto 383 se fijaron tres tipos de zonas francas: permanentes, permanentes especiales y transitorias. Este decreto fija los montos permanentes mínimos de inversión y de creación de empleo; para las permanentes especiales o uniempresariales elimina el requisito de área 
mínima de 20 hectáreas para la declaratoria de tales y declara las transitorias de manera temporal -en lugares donde se celebran ferias, exposiciones, congresos y seminarios de carácter internacional.

También en 2007 con el Decreto 4051 se estableció la opción para las sociedades que estén desarrollando un proyecto, dando la opción de transformarse en zonas francas permanentes especiales; siempre que su inversión nueva sea de US\$178.2 millones, tengan un patrimonio líquido superior a US\$38.6 millones y puedan duplicar su renta gravable.

En Mayo 24 de 2010, de 112 solicitudes de zonas francas, tenían concepto de viabilidad 70 (Tabla 2) y en trámite se encontraban 22; además había 20 en trámite por otros conceptos. Al finalizar el año se habían declarado 79 zonas francas en el país, de las cuales 32 se clasifican en la categoría de permanentes y 47 en las permanentes especiales o uniempresariales.

Las zonas francas se concentran en los departamentos de Cundinamarca y Bolívar con el $41 \%$ del total, es decir 32 de ellas, a diferencia del 54\% que tenían antes de 2005 (tabla 1) y que compartían estos departamentos con el Valle del Cauca cuando cada uno tenía dos zonas francas de las once que existían. En general, las zonas francas pasaron de 11 en 2005 a 79 en 2010 , y dentro de ellas las uniempresariales dieron un salto de 5 en 2007 a 47 en 2010 y las permanentes pasaron de 11 a 32 en el mismo período.

En la figura 1 se puede analizar con mayor claridad lo que sucedió con las solicitudes de viabilidad favorable de las zonas francas a partir de la Ley 1004 de 2005. Las 70 que obtuvieron concepto de favorabilidad adquirieron unos compromisos de inversión por US\$5952.6 millones, creación de 45.353 empleos directos, 93.890 indirectos, 19.956 vinculados y 13.428 no especificados en un área de 2.860 hectáreas.

En las solicitudes de zonas francas en trámite, vale la pena destacar las cifras que muestra el Ministerio de Comercio. Las 22 ofrecían realizar una inversión de US\$2.551 millones, la creación de 11.149 empleos directos, 7.250 indirectos, 1.089 vinculados y 2.832 no especificados en 1.390 hectáreas. Del total de 112 solicitudes presentadas a mayo 24 de 2010, entre las 92 zonas francas con concepto de viabilidad favorable y en trámite, se ve que los US $\$ 8.503,6$ millones, representan el 10.5\% de la oferta de inversión y el $90 \%$ del empleo directo, mientras que las 5 negadas con US\$71.773.9 representan el $88.5 \%$ de la oferta de inversión, aunque solo el 2,6 del empleo directo ofrecido.

En la figura 1 puede verse el comportamiento de las zonas francas entre los años 2006 y 2010 , teniendo en cuenta que fue 2007 el año en que comienza la nueva etapa de esta actividad económica y a 2006 solo había 11 de ellas. 


\section{Ramiro César Barajas Gómez}

Beneficios tributarios y su relación con el déficit fiscal en Colombia durante el período comprendido entre los años 2005 y

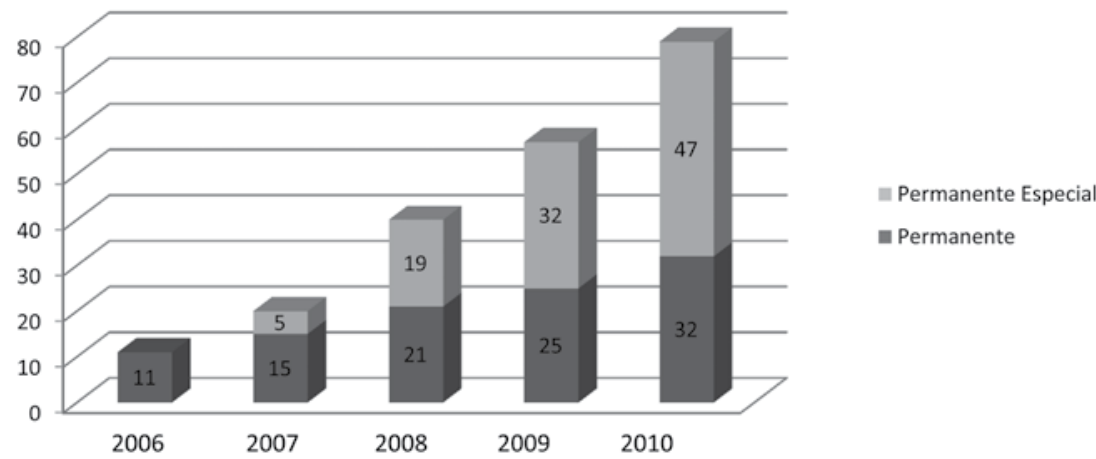

Figura 1. Evolución de las zonas francas entre 2006 y 2010. Tomado de Ramos y Rodríguez, 2011.

La zonas francas pasaron de ser 11 en 2006, todas permanentes, a 15 de ellas en 2007 con 5 permanentes especiales, creciendo en 2008 a 21 y 19 e incrementándose luego a 25 y 32 en 2009, finalizando en 2010 con 32 y 47 respectivamente. Esto significa un total de 79 zonas francas funcionando por todo el país.

Metas de empleo

Tabla 3. Compromisos de empleo e inversión en zonas francas. Fuente: Ramos y Rodríguez, 2011.

\begin{tabular}{|l|l|l|l|l|l|l|l|l|}
\hline \multicolumn{8}{|c|}{ Compromiso de empleo e inversión en zonas francas } \\
\hline & \multicolumn{9}{c|}{ Compromiso de Empleo } & \multicolumn{7}{c|}{ Compromiso de inversión } \\
\hline & Directo & Ejecución & $\begin{array}{l}\text { Indi- } \\
\text { recto }\end{array}$ & $\begin{array}{l}\text { Ejecu- } \\
\text { ción }\end{array}$ & Total & $\begin{array}{l}\text { Ejecu- } \\
\text { ción }\end{array}$ & Billones & $\begin{array}{l}\text { Ejecu- } \\
\text { ción }\end{array}$ \\
\hline $\begin{array}{l}\text { ZF } \\
\text { Permanentes }\end{array}$ & 24.529 & $1,40 \%$ & 70.276 & $2,60 \%$ & 94.805 & $2,30 \%$ & 1,5 & $21,60 \%$ \\
\hline $\begin{array}{l}\text { ZF Permanen- } \\
\text { tes Especiales }\end{array}$ & 8.922 & $65,10 \%$ & 12.155 & $196,70 \%$ & 21.147 & & 10,7 & $49,90 \%$ \\
\hline Total & 33.521 & $18,50 \%$ & 82.431 & $31,20 \%$ & 115.952 & $27,60 \%$ & 12,2 & $46,30 \%$ \\
\hline
\end{tabular}

Fuente: Ramos y Rodríguez, 2011.

Se aprecia en la Tabla 3 que el compromiso adquirido por las zonas francas creadas a partir de 2007 en cuanto a generación de empleo fue de 115.952 nuevos puestos de trabajo, de los cuales 33.521 serían directos y 82.431 indirectos (Ramos y Rodríguez, 2011). Al finalizar 2010, solo se había logrado la ejecución del $18.5 \%$ de los directos y $31.2 \%$ de los indirectos. Nótese que, de la obligación adquirida en las zonas francas permanentes, solo se cumplió el $1.4 \%$ de la meta de empleos directos y el 2,6\% de los indirectos. En las 
permanentes especiales se ofrecieron menos empleos directos y su ejecución fue más alta. En total, se cumplió el $27.6 \%$ de la meta de empleo.

\section{Metas de inversión}

De la misma forma, en la Tabla 4 se colige que, si en empleo no se cumplieron las metas, en cuanto a inversión tampoco lo harían; pues de la inversión programada al finalizar 2010, se contabilizaron compromisos por $\$ 12.2$ billones, de los cuales $\$ 10.7$ billones corresponden a las zonas francas permanentes especiales o uniempresariales y solo $\$ 1.5$ billones de las permanentes. De la meta total establecida solamente se ejecutó el $46.3 \%$ o sea, $\$ 5.6$ billones. De la misma manera que en los compromisos de empleo, del nivel de ejecución programado en inversión en las permanentes únicamente se logró el $21.6 \%$, mucho menor que el de las uniempresariales que fue del 49.9\%. Al parecer, según Ramos y Rodríguez (2011), la causa de la brecha en los niveles de ejecución en la inversión programada, está en que las permanentes tienen para el cumplimiento de las metas un plazo de cinco años, mientras que las uniempresariales tienen tres.

Como puede observarse, aún está lejos el cumplimiento de metas en inversión y generación de empleo según lo propuesto por la legislación. Es importante anotar que en el año 2000 había 232 empresas establecidas en zonas francas y pasó a 391 en 2005, año de la expedición de la nueva Ley, y a 564 en 2009. El mayor número de empresas se encuentra en el sector industrial de bienes y servicios y en el comercio. Sin embargo, el número de firmas en este último sector se mantiene prácticamente igual desde 2004, como consecuencia de no tener tarifa diferencial en renta sino que tributa a la tarifa general del $33 \%$. De las 21 zonas francas permanentes creadas y declaradas entre 2007 y 2010, 17 son industriales, mientras que en las uniempresariales se nota una mayor diversidad de actividades económicas, pues en 2010 de las 47 clasificadas el $40 \%$ eran industriales, el $26 \%$ de servicios, el $23 \%$ agroindustriales y el $11 \%$ de servicios portuarios. Entre las agroindustriales sobresalen las de producción de biocombustibles y en el de servicios se destacan las de prestación de servicios de salud (Ramos y Rodríguez, 2011).

\section{Beneficios tributarios en las zonas francas}

La zonas francas reciben beneficios tributarios en el impuesto de renta (tarifa diferencial del $15 \%$ para actividades diferentes a las comerciales y hasta el año 2010, una deducción por inversión en activos fijos), en el de remesas, en el IVA a las importaciones en el nivel nacional y en el territorial el tratamiento especial está dado por el impuesto de industria y comercio. Los beneficios totales se encuentran el Artículo 5 de la Ley 1004 de 2005 mencionados anteriormente. Según la Tabla 4, y con base en las declaraciones de renta suministradas a Ramos y Rodríguez (2011), se presenta el impuesto de renta pagado por las empresas que operan dentro de las zonas francas, el cual se mide como 


\section{Ramiro César Barajas Gómez}

Beneficios tributarios y su relación con el déficit fiscal en Colombia durante el período comprendido entre los años 2005 y 2010, artículo producto de la investigación

proporción del recaudo total del tributo. Nótese que entre los años $2000 \mathrm{y}$ 2009 , los pagos se situaron en alrededor del $1 \%$ del total de recaudo del impuesto y que la gran proporción provino de las actividades comerciales que, como ya se dijo, tributan al $33 \%$.

Llama la atención el hecho de que la declaratoria de 68 nuevas zonas francas en los últimos años, no se refleja en el pago del impuesto de renta a cargo de ellas que cayó en términos reales $9.5 \%$ en $2008,10.7 \%$ en 2009. (...) Hasta el año 2006 todas las actividades desarrolladas en estas zonas liquidaban el impuesto con la tarifa plena del 35\%. Con la nueva normatividad, a partir de 2007 se observa una reducción gradual de las tarifas en todas las actividades deferentes a las comerciales, hasta alcanzar el nivel de la tarifa estatutaria del 15\% al final de 2009 (Ramos y Rodríguez, 2011:13).

Tabla 4. Impuesto de renta pagado por las empresas ubicadas dentro de las zonas francas en millones de pesos.

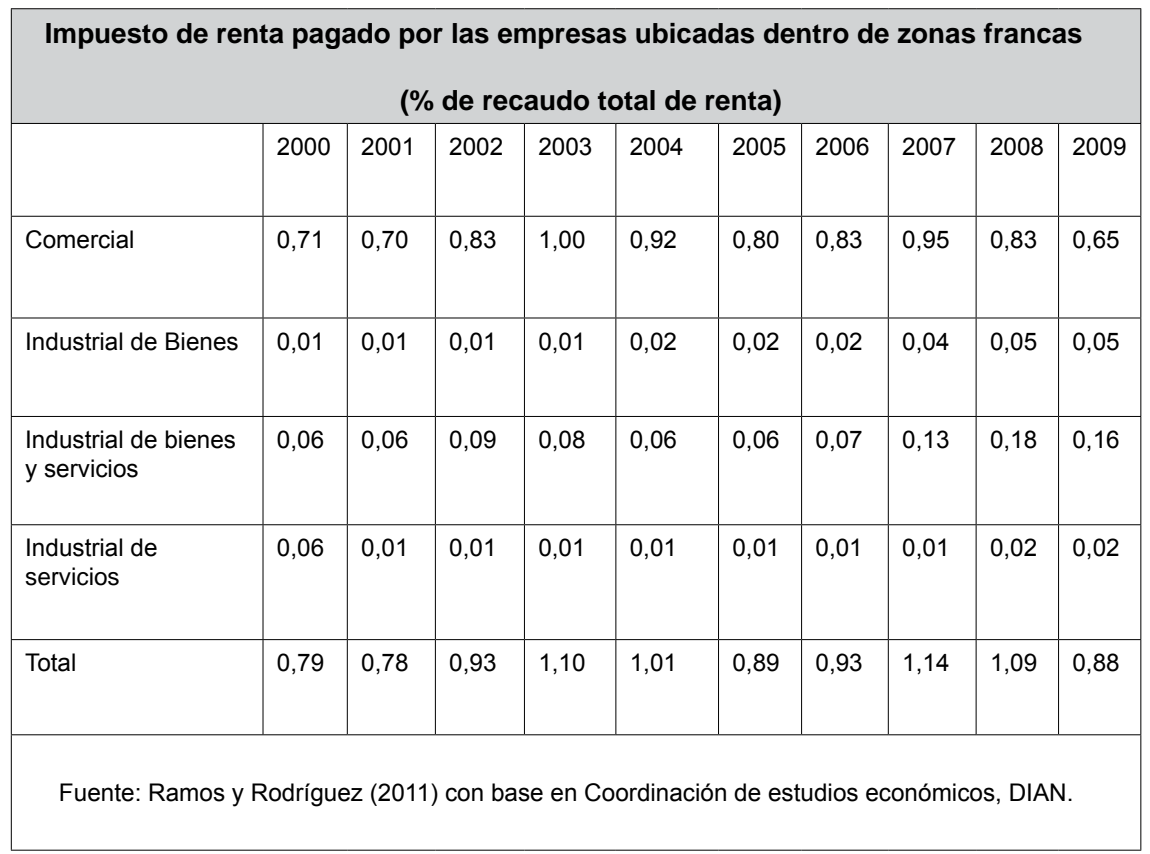

En la Tabla 4 se puede ver que las empresas comerciales son las que más tributan y cuyo monto aportado al fisco vino en aumento hasta el año 2009, cuando tuvo una leve disminución. Las industriales de bienes y las de bienes $\mathrm{y}$ servicios presentaron un permanente incremento y las industriales de servicios, a pesar de tener variaciones, terminaron aumentando sus tributos. 
En general, el comportamiento del impuesto pagado por las empresas que se encuentran dentro de las zonas francas fue de ascenso hasta 2008 y 2009 , cuando seguramente por el efecto de la crisis sumado a las ventajas tributarias otorgadas comenzó a disminuir el pago al fisco.

De la Tabla 5 se desprende que los beneficios tributarios en renta solo comienzan a notarse a partir de 2007 cuando suman $\$ 29.602$ millones, que significa el $0.1 \%$ del impuesto de renta y llegó en 2009 a $\$ 67.661$ millones, o sea el $0.2 \%$ del recaudo de renta. Pero se debe aclarar que este beneficio no lo tuvieron las empresas comerciales por los motivos varias veces anotados.

En cambio, los beneficios por deducción por inversión en activos fijos originó una ayuda tributaria que ascendió de \$34.373 millones en 2004 a \$ 159.711 en 2009; o sea, un $0.6 \%$ del total del recaudo. Lo anterior llevó a Juan Camilo Restrepo a afirmar:

Un caso es el de las zonas francas, pero hay otra exención más aberrante, la deducción del $40 \%$ para la adquisición de activos productivos, que vale al año $\$ 3,6$ billones, para premiar la importación de equipos que de todas maneras se hubiera hecho al amparo de un dólar muy barato" (El Espectador 10-05-2009); y a Guillermo Perry en el mismo periódico y en la misma entrevista: "las empresas en estas zonas francas, tienen beneficios exorbitantes, pueden bajar la tarifa de renta de $33 \%$ a $15 \%$ y utilizar el $40 \%$ de deducción de sus inversiones.

Entonces puede quedar pagando $8 \%$ o $9 \%$, es decir, que no contribuye para nada. Es una inequidad dramática que afecta los recaudos totales, y se prolonga con los contratos de estabilidad jurídica, entonces realmente se está creando un Frankenstein.

En total, los concesiones tributarias pasaron de ser $\$ 34.048$ millones $(0.2 \%)$ en 2004 a $\$ 227.372$ millones $(0.8 \%)$ en 2009 , mostrando un significativo aumento del $668 \%$, en tan solo cinco años.

Se nota también que la mayor deducción por inversión en activos fijos la obtuvieron las empresas comerciales, pues el beneficio tributario para estas empresas ascendió de $0.1 \%$ en 2004 , al $0.3 \%$ del recaudo en renta en 2009 . La aplicación del instrumento se intensificó a partir de 2007 por el incremento del $30 \%$ al $40 \%$ en el porcentaje de las inversiones deducibles de renta.

La misma explicación tiene el uso del beneficio de las demás empresas que operan en las zonas francas. 


\section{Ramiro César Barajas Gómez}

Beneficios tributarios y su relación con el déficit fiscal en Colombia durante el período comprendido entre los años 2005 y 2010, artículo producto de la investigación

Tabla 5. Beneficios tributarios totales de las zonas francas, millones de pesos

\begin{tabular}{|c|c|c|c|c|c|c|c|}
\hline \multicolumn{8}{|c|}{ Beneficios tributarios totales de las zonas francas, millones de pesos } \\
\hline & & 2004 & 2005 & 2006 & 2007 & 2008 & 2009 \\
\hline & Comercial & $(1.092)$ & $(748)$ & $(786)$ & $(803)$ & $(919)$ & $(938)$ \\
\hline & Industrial de Bienes & - & - & - & 9.927 & 13.202 & 15.076 \\
\hline \multirow[t]{4}{*}{ Renta } & $\begin{array}{l}\text { Industrial de Bienes } \\
\text { y Servicios }\end{array}$ & 766 & 244 & 51 & 17.514 & 30.036 & 45.904 \\
\hline & $\begin{array}{l}\text { Industrial de ser- } \\
\text { vicios }\end{array}$ & $(325)$ & - & - & 2.964 & 6.009 & 7.619 \\
\hline & Total & $(325)$ & $(504)$ & (735) & 29.602 & 48.328 & 67.661 \\
\hline & Comercial & 21.368 & 22.196 & 37.240 & 67.227 & 65.268 & 72.061 \\
\hline $\begin{array}{l}\text { Deduc- } \\
\text { ción }\end{array}$ & Industrial de Bienes & 589 & 3.596 & 5.577 & 7.312 & 8.809 & 21.578 \\
\hline $\begin{array}{l}\text { por Inver- } \\
\text { sión }\end{array}$ & $\begin{array}{l}\text { Industrial de Bienes } \\
\text { y Servicios }\end{array}$ & 12.387 & 6.921 & 7.497 & 44.080 & 67.706 & 57.577 \\
\hline \multirow[t]{3}{*}{$\begin{array}{l}\text { en Activos } \\
\text { Fijos }\end{array}$} & $\begin{array}{l}\text { Industrial de ser- } \\
\text { vicios }\end{array}$ & 29 & 113 & 35 & 5.673 & 4.915 & 7.885 \\
\hline & Total & 34.373 & 32.826 & 50.349 & 124.291 & 146.697 & 159.711 \\
\hline & Comercial & 20.276 & 21.447 & 36.454 & 66.424 & 64.349 & 71.732 \\
\hline Total & Industrial de Bienes & 589 & 3.596 & 5.577 & 17.239 & 22.011 & 36.654 \\
\hline \multirow[t]{3}{*}{ Beneficios } & $\begin{array}{l}\text { Industrial de Bienes } \\
\text { y Servicios }\end{array}$ & 13.154 & 7.165 & 7.548 & 61.593 & 97.741 & 103.481 \\
\hline & $\begin{array}{l}\text { Industrial de ser- } \\
\text { vicios }\end{array}$ & 29 & 113 & 35 & 8.637 & 10.924 & 15.504 \\
\hline & Total & 34.048 & 32.322 & 49.614 & 153.893 & 195.025 & 227.372 \\
\hline
\end{tabular}

De la información de la Tabla 5 se desprende que, si bien es cierto que los beneficios obtenidos por las empresas establecidas en las zonas francas no son tan importantes en términos porcentuales, en términos absolutos no son nada despreciables, pues sumados a las demás ventajas que se otorgan a las demás empresas, aunados a la evasión y la elusión, sí son de consideración. Sin embargo, tampoco es notorio el aporte en términos de recaudo, a pesar de haber 60 nuevas zonas francas desde 2007 como consecuencia de los mismos motivos.

Llama la atención la baja ejecución de los compromisos adquiridos en materia de inversión y de generación de empleo, especialmente en las zonas francas permanentes, lo que hace pensar en que las metas no serán cumplidas y tampoco hay una manera de "cobrarlas" por parte del gobierno. Con el dinamismo que 
han presentado las zonas francas, es previsible que el costo fiscal del beneficio tributario en la tarifa de renta no continúe bajo en el mediano plazo.

En materia de impuestos el nuevo régimen de zonas francas genera un tratamiento inequitativo frente a las actividades económicas que se desarrollen por fuera de ellas. Como lo señala Fedesarrollo (2008), resulta injustificado que empresas con características similares en tamaño, actividad y ubicación tributen con tarifas relativamente más altas en el impuesto de renta. Esta situación podría desincentivar las inversiones en proyectos que se pretendan ejecutar por fuera de estas zonas y establece las condiciones para que las empresas existentes evalúen la posibilidad de ubicar parte de sus actividades bajo ese régimen, con lo cual se genera un problema de asignación de recursos (Ramos y Rodríguez, 2001: 17)

Sector externo

Tabla 6. Balanza Comercial de Colombia 2005-2010 en millones de dólares

\begin{tabular}{|l|l|l|l|l|l|}
\hline \multicolumn{5}{|c|}{ Malanza Comercial de Colombia 2005-2010 } \\
\hline \multicolumn{5}{|c|}{ Millones de dólares } \\
\hline Año & $\begin{array}{l}\text { Exportaciones } \\
\text { Importaciones } \\
\text { Balanza }\end{array}$ & Variación \% & Importaciones & Variación \% & Balanza \\
\hline 2005 & $21.190,4$ & & $19.798,9$ & & $1.391,5$ \\
\hline 2006 & $24.391,0$ & 15,1 & $24.534,0$ & 23,9 & $-143,0$ \\
\hline 2007 & $29,991.3$ & 22,9 & $30,815.7$ & 25,6 & -824.3 \\
\hline 2008 & $37.625,9$ & 25,4 & $37.155,4$ & 20,6 & 470,5 \\
\hline 2009 & $32.853,0$ & $-12,7$ & $31.187,8$ & $-16,1$ & $1.665,2$ \\
\hline 2010 & $39.820,0$ & 21,2 & $38.351,0$ & 23,0 & $1.469,0$ \\
\hline $\begin{array}{l}\text { Fuente: DIAN - DANE } \\
\text { Elaboró: Coordinación de Estudios Económicos - DIAN. }\end{array}$ & \\
Cálculos del autor & & & \\
\hline
\end{tabular}

Una mirada al sector externo (Tabla 6), en el que tradicionalmente se han desempeñado las zonas francas, muestra que este ha venido en aumento. Sin embargo, la Balanza Comercial no ha favorecido el crecimiento de la economía en todos los años. Pues en 2006 y 2007, cuando el crecimiento del PIB fue muy notorio, se presentó deficitaria, indicando que las importaciones restaron a la producción nacional. En 2008, año de la manifestación de la crisis, fue ligeramente positiva y en 2009 , a pesar de que tanto las exportaciones como las importaciones disminuyeron, aparece nuevamente positiva. Tendría también un crecimiento significativo en 2010, a pesar de que las importaciones aumentaron más que las exportaciones. Seguramente es importante mencionar que las exportaciones suman al PIB y las importaciones restan, y que las primeras crean empleo en el país y las segundas lo hacen en el extranjero. 


\section{Ramiro César Barajas Gómez}

Beneficios tributarios y su relación con el déficit fiscal en Colombia durante el período comprendido entre los años 2005 y 2010, artículo producto de la investigación

Como se anotó, debe resaltarse la variación que se presentó en las exportaciones que pasaron de un incremento entre 2007 y 2008 de $25.4 \%$, a una notoria disminución del $12.7 \%$ entre 2008 y 2009. De la misma manera, las importaciones sufrieron una reducción en 2009 de 16.1\%. Fue afortunado que la merma en las exportaciones haya sido menor que el de las importaciones, porque permitió tener una Balanza Comercial positiva, aunque ya para el año 2010 haya disminuido en términos reales en comparación con 2009 y se haya ubicado en US\$1.469 millones.

Tabla 7. Recaudos externos 2005-2010

\begin{tabular}{|c|c|c|c|c|c|}
\hline \multicolumn{6}{|c|}{ RECAUDOS EXTERNOS 2005-2010 (Millones de pesos) } \\
\hline & $\mathrm{CIF}$ & ARANCEL & IVA & TOTAL & VARIACIÓN \\
\hline AÑO & PESOS & AUTOLIQUIDADO & AULTOLIQUIDADO & RECAUDOS & $\%$ \\
\hline 2005 & 49.212.622,57 & $2.872 .377,23$ & $6.053 .733,60$ & $8.926 .110,83$ & \\
\hline 2006 & $61.818 .063,46$ & $3.612 .646,57$ & $7.996 .878,55$ & $11.609 .525,11$ & 30,1 \\
\hline 2007 & $68.277 .784,01$ & $4.132 .634,85$ & $8.831 .559,90$ & 12.964.194,75 & 11,7 \\
\hline 2008 & $77.957 .872,16$ & $4.233 .122,41$ & $9.614 .372,04$ & $13.847 .494,45$ & 6,8 \\
\hline 2009 & $70.678 .501,90$ & $3.933 .470,29$ & $8.111 .419,19$ & 12.044.889,48 & 13 \\
\hline $2010^{*}$ & $77.041 .478,90$ & $4.645 .357,30$ & $9.506 .068,50$ & $14.151 .425,80$ & 17,5 \\
\hline \multicolumn{6}{|c|}{$\begin{array}{l}\text { *: Corresponde a lo autoliquidado por los importadores en las declaraciones de importación } \\
\text { Fuente: Declaraciones de importación. SAS. DIAN. Coordinación de Estudios Económicos. } \\
\text { Cálculos del autor. }\end{array}$} \\
\hline
\end{tabular}

Del mismo modo que esa actividad externa de la Balanza Comercial muestra la contribución al PIB, también tiene un comportamiento significativo en materia de recaudos externos (como se ve en la Tabla 7). Estos recaudos han venido en aumento a pesar de no ser constantes, pero muestra cuál ha sido el comportamiento del ciclo de los negocios y siendo siempre más importante el recaudo por IVA que por aranceles, pues es aproximadamente el doble.

No deja de llamar la atención el disímil comportamiento en la variación año a año, pues el menoscabo que presenta el recaudo total entre 2005 y 2006 fue de $30.1 \%$ y disminuye al cambiar a 2007 en $11.7 \%$, y luego a $6.8 \%$ en 2008 , pasando a $13 \%$ en 2009 y a $17.5 \%$ en 2010 . 
Tabla 8. Ingreso y salida de mercancías de diez zonas francas

\begin{tabular}{|c|c|c|c|c|}
\hline \multicolumn{5}{|c|}{ INGRESO Y SALIDA DE MERCANCÍA DE DIEZ ZONAS FRANCAS } \\
\hline \multicolumn{5}{|c|}{ PERMANENTES* 2005-2009 Miles de dólares } \\
\hline & Salidas FOB & Variación & Ingresos CIF & Variación \\
\hline AÑO & Zonas francas & $\%$ & Zonas francas & $\%$ \\
\hline 2005 & 6.198 .529 & & 4.782 .939 & \\
\hline 2006 & 8.480 .256 & 36,8 & 7.336 .815 & 53,4 \\
\hline 2007 & 9.343 .963 & 10,2 & 7.864 .310 & 7,2 \\
\hline 2008 & 11.510 .642 & 23,2 & 9.541 .342 & 21,3 \\
\hline 2009 & 9.188 .586 & $-20,2$ & 8.481 .084 & $-11,1$ \\
\hline \multicolumn{5}{|c|}{$\begin{array}{l}\text { *Barranquilla, Bogotá, Cartagena, Cúcuta, La Candelaria. Palmaseca, Rionegro, } \\
\text { Eje Cafetero, Pacífico y Santa Marta. } \\
\text { Fuente DIAN-DANE } \\
\text { Cálculos del autor }\end{array}$} \\
\hline
\end{tabular}

Según lo señalado en la Tabla 8 , la cual comprende las operaciones de ingreso y salidas de mercancías entre las Zonas Francas y el resto del mundo, el Territorio Aduanero Nacional (TAN.), otra Zona Franca y usuarios de la misma Zona Franca, puede observarse que, a pesar del crecimiento dispar tanto de las salidas como de los ingresos de mercancías, no son tan significativos frente al total de las importaciones y exportaciones. La disminución en 2009 en salidas e ingresos de mercancías, obedece seguramente a la crisis mundial presentada en el año inmediatamente anterior.

Tabla 9. Aporte de diez zonas francas permanentes al Comercio Exterior 2005-2009

\begin{tabular}{|c|c|c|c|c|c|c|}
\hline \multicolumn{7}{|c|}{$\begin{array}{l}\text { APORTE DE DIEZ ZONS FRANCAS PERMANENTES AL COMERCIO EXTERIOR } \\
\qquad 2005-2009\end{array}$} \\
\hline \multicolumn{7}{|c|}{ Millones de dólares } \\
\hline Año & $\begin{array}{l}\text { Exportacio- } \\
\text { nes }\end{array}$ & Salidas ZF & Aporte \% & $\begin{array}{l}\text { Importacio- } \\
\text { nes }\end{array}$ & $\begin{array}{l}\text { Ingresos } \\
\text { a ZF }\end{array}$ & Aporte \% \\
\hline 2005 & $21.190,4$ & $6.198,5$ & 29,25 & $19.798,9$ & $4.782,9$ & 24,15 \\
\hline 2006 & $24.391,0$ & $8.480,3$ & 34,76 & $24.534,0$ & $7.336,8$ & 29,90 \\
\hline 2007 & $29.991,3$ & $9.344,0$ & 31,15 & $30.815,7$ & $7.864,3$ & 25,52 \\
\hline 2008 & $37.625,9$ & $11.510,6$ & 30,59 & $34.155,4$ & $9.541,3$ & 25,67 \\
\hline 2009 & $32.853,0$ & $9.188,6$ & 29,96 & $31.187,8$ & $8.481,1$ & 27,19 \\
\hline
\end{tabular}

Para ver qué tanto aporte hacen las diez zonas francas permanentes consideradas en la Tabla 8, se hace necesario comparar el ingreso y la salida de mercancías de dichas zonas francas con las exportaciones y las importaciones totales, tal 


\section{Ramiro César Barajas Gómez}

Beneficios tributarios y su relación con el déficit fiscal en Colombia durante el período comprendido entre los años 2005 y 2010, artículo producto de la investigación

como aparece en la Tabla 9. Lo que aquí se ve, es que el aporte tanto de ingreso como de salida de mercancías es más notorio en 2006; es decir, un año después de la entrada en vigencia de la nueva legislación de zonas francas. Pero en los demás años, incluido el 2005, han variado solo entre el $29.2 \%$ y el $31.1 \%$ en el aporte a las exportaciones (solo $1.9 \%$ más).

En cuanto al ingreso de mercancías, salvo el año 2006 -y tal como sucedió con las salidas- los aportes tuvieron un comportamiento similar al variar entre el $24.5 \%$ y el $27.1 \%$ (solo $2.6 \%$ más), haciendo énfasis en que dichas mercancías pueden estar rotando entre usuarios de la misma zona franca o entre zonas francas.

No puede afirmarse con total certeza entonces, que esas cifras de salida e ingreso de mercancías en zonas francas suman en su totalidad a las exportaciones y a las importaciones, por cuanto se presentan salidas e ingresos a las zonas francas para que se les dé un valor agregado o presten un servicio, (tales como mercancías que se procesan, transforman o reparan y que son contabilizadas como entradas o salidas de las zonas francas, según el caso) pero no como importaciones y exportaciones.

\section{Recaudos totales}

Tabla 10. Recaudo (1) total de los ingresos administrados por la DIAN 2005-2010

(Millones de pesos corrientes)

\begin{tabular}{|l|l|l|l|l|}
\hline \multicolumn{5}{|c|}{ RECAUDO (1) TOTAL DE LOS INGRESOS ADMINISTRADOS POR LA DIAN } \\
2005-2010 \\
\hline \multicolumn{5}{|c|}{ (Millones de pesos corrientes) } \\
\hline AÑO & $\begin{array}{l}\text { IMPTO. RENTA } \\
\text { (CUOTAS) }\end{array}$ & $\begin{array}{l}\text { IVA DECLA- } \\
\text { RACIONES (2) }\end{array}$ & $\begin{array}{l}\text { RETENCIONES } \\
(3)\end{array}$ & EXTERNOS (4) \\
\hline 2005 & 8.049 .320 & 8.889 .595 & 14.583 .852 & 9.287 .829 \\
\hline 2006 & 9.975 .860 & 10.887 .932 & 16.609 .329 & 12.264 .178 \\
\hline 2007 & 10.222 .034 & 13.097 .253 & 19.345 .803 & 13.335 .929 \\
\hline 2008 & 10.142 .816 & 14.322 .891 & 21.869 .890 & 14.161 .145 \\
\hline 2009 & 13.510 .157 & 14.797 .056 & 22.487 .767 & 12.727 .699 \\
\hline 2010 & 9.419 .571 & 16.577 .992 & 24.139 .602 & 14.562 .960 \\
\hline
\end{tabular}




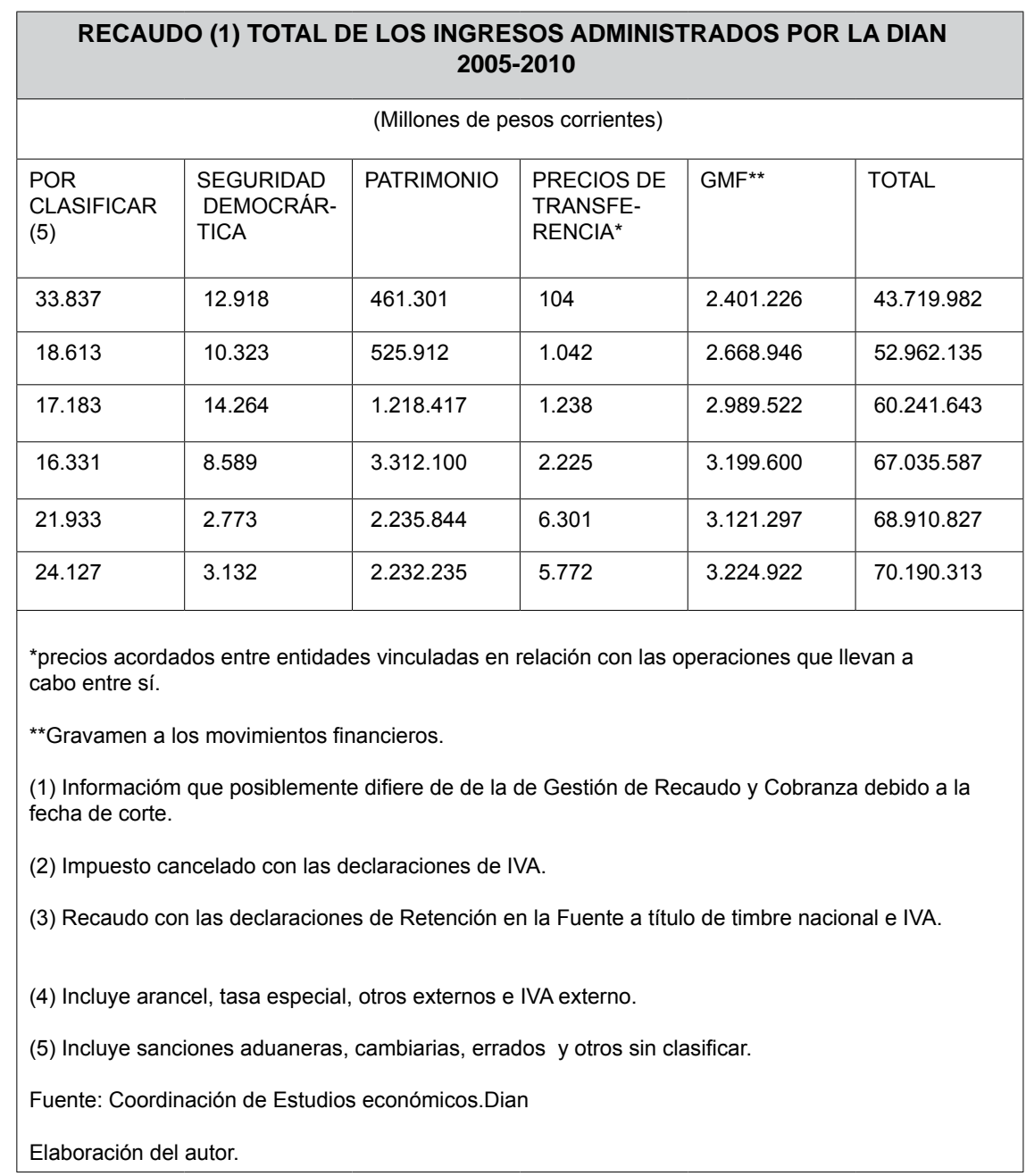

Los recaudos totales administrados por la DIAN (Tabla 10) muestran claramente un permanente incremento a precios corrientes, lo que hace pensar que la disminución en recaudos externos del año 2009 fue consecuencia de la disminución de las importaciones, pues fue el único año en que presentó una rebaja. Sin embargo, otros ítems que también presentaron decremento para este año son el de seguridad democrática, patrimonio y gravamen a los movimientos financieros.

Aún así, a pesar de que el total del recaudo aumentó en todos los años del período considerado, es necesario resaltar que el impuesto de renta tuvo un marcado descenso pasando de $\$ 13.5$ billones en 2009 , a $\$ 9.4$ billones en 2010 , es decir, una merma del $30.3 \%$, lo cual es bastante considerable. También es 


\section{Ramiro César Barajas Gómez}

Beneficios tributarios y su relación con el déficit fiscal en Colombia durante el período comprendido entre los años 2005 y 2010, artículo producto de la investigación

de resaltar el comportamiento creciente del impuesto de seguridad democrática en los primeros tres períodos, y la disminución variable en los siguiente tres.

\section{Comportamiento de la deuda}

Tabla 11. Deuda neta del SPNF (Sector público no financiero).

\begin{tabular}{|c|c|c|c|c|c|c|c|c|c|}
\hline \multicolumn{10}{|c|}{ DEUDA NETA DEL SPNF (SECTOR PÚBLICO NO FINANCIERO)* } \\
\hline & INTERNA & EXTERNA & TOTAL & INTERNA & EXTERNA & TOTAL & INTERNA & EXTERNA & TOTAL \\
\hline AÑO & \multicolumn{3}{|c|}{$\begin{array}{l}\text { (Miles de Millones } \\
\text { de pesos) }\end{array}$} & \multicolumn{3}{|c|}{ (Porcentaje del PIB) } & \multicolumn{3}{|c|}{ (Participación) } \\
\hline 2005 & 72.040 & 53.343 & 125.383 & 21,5 & 15,9 & 37,4 & 57,5 & 42,5 & 100 \\
\hline 2006 & 73.597 & 57.961 & 131.558 & 19,2 & 15,1 & 34,3 & 55,9 & 44,1 & 100 \\
\hline 2007 & 77.953 & 56.259 & 134.212 & 18,1 & 13 & 31,1 & 58,1 & 41,9 & 100 \\
\hline 2008 & 82.657 & 63.831 & 146.489 & 17,3 & 13,3 & 30,6 & 56,4 & 43,6 & 100 \\
\hline 2009 & 98.785 & 71.839 & 170.624 & 19,4 & 14,1 & 33,6 & 57,9 & 42,1 & 100 \\
\hline 2010 & 118.175 & 71.049 & 189.224 & 21,6 & 13 & 34,6 & 62,5 & 37,5 & 100 \\
\hline \multicolumn{10}{|c|}{$\begin{array}{l}\text { ^El ejercicio de neteo consiste en eliminar de la deuda interna bruta los bonos de la nación en poder } \\
\text { del Resto del SPNF y los pagarés del Gobierno Nacional con entidades públicas. } \\
\text { Fuente: SGEE (Subgerencia de estudios económicos del sector público Boletín № } 38 \text { ), Banco de la } \\
\text { República. }\end{array}$} \\
\hline
\end{tabular}

Por supuesto, un tema relacionado con los recaudos para sufragar los gastos del gobierno es la deuda del sector público, tanto a nivel interno como externo. Al comparar estos conceptos se comienza a tener una idea clara de lo que puede significar el déficit fiscal. En la Tabla 11 se ve cómo ha venido acrecentándose la deuda interna y externa del sector público no financiero, y la forma como se ha venido incrementando a un ritmo más acelerado la deuda interna que la externa, lo cual es notorio en la proporción deuda interna/PIB, frente a deuda externa/ PIB: en 2010 esta es de $21.6 \%$ para la primera, frente a 13\% de la segunda, y una participación en la deuda total de $62.5 \%$ y $37.5 \%$ respectivamente.

\subsection{Beneficios en renta}

En el año gravable 2009 se observa que el valor total de las rentas exentas solicitadas por las personas jurídicas ascendió a $\$ 5.703 \mathrm{~mm}$, presentando una caída de $2,9 \%$ respecto al valor registrado en el año 2008 , que puede explicarse por la disminución del valor de las rentas exentas solicitadas por los contribuyentes en relación al valor registrado por este concepto durante el año 2008 (-14,0\%)" (Parra et al, 2010:18).El monto total de las rentas exentas para los grandes contribuyentes ascendió en el año gravable 2009 a $\$ 3.555 \mathrm{~mm}$, que representa un decrecimiento del $12,0 \%$ respecto del total registrado durante el año inmediatamente anterior. De este monto el $63,5 \%$ corresponde a la participación del sector privado y el $36,5 \%$ 
al sector público/mixto. Es importante resaltar la diferencia en la composición respecto al año 2008, la cual representó el 53,4\% para el sector público y el 46,6\% para el sector privado, que se traduce en un incremento en la participación de las rentas exentas de los grandes contribuyentes del sector privado del $19,8 \%$ en el año gravable 2009 (Parra et al., 2010:19).

\section{Balance fiscal}

En la Tabla 12 puede observarse el comportamiento del Balance Fiscal del Gobierno Nacional Central entre 2005 y 2010. Aquí se confirma el ya consabido problema de la diferencia permanente en la información. En dicha tabla puede evidenciarse que si bien es cierto que los ingresos aumentan año a año, también lo es que las cifras no son iguales de una institución a otra. Este es el caso de la DIAN y el Ministerio de Hacienda. No obstante, ateniéndose a lo que dicen estos cuadros, se encuentra que los ingresos totales ( $\sin$ causados) del Gobierno Nacional Central (GNC) en seis años pasan de ser \$45.7 billones en 2005 a $\$ 74.9$ billones en 2010 con un incremento del 64\%, siendo, como es de esperarse, los ingresos tributarios el componente más importante; pues de $\$ 42.3$ billones en 2005 pasaron a $\$ 67.4$ billones o sea, un aumento del 58\%.

Hasta aquí el lector desprevenido no tendría inconveniente en la lectura de la tabla, pero cuando se pasa a observar los pagos totales que cambian de $\$ 59.1$ billones en 2005 a $\$ 93.7$ billones en 2010 , o sea un incremento del $65 \%$, comienza a pensarse que aparecen los inconvenientes para el GNC. Esto debido a que, cuando los gastos son mayores que los ingresos, en todas partes se dice que hay un faltante que se ha dado en llamar déficit. Es decir, mientras los ingresos en 2005 fueron $\$ 45.7$ billones, los pagos llegaron a $\$ 59.2$ billones; en 2010 estos mismos ítems se presentan con $\$ 74.9$ y $\$ 93.7$ billones respectivamente, mostrando que si bien es cierto que los ingresos crecieron en estos seis años, los pagos también aumentaron más que proporcionalmente.

Tabla 12. Balance Fiscal Gobierno Nacional Central 2005-2010 (Miles de millones de pesos)

\begin{tabular}{|l|l|l|l|l|l|l|}
\hline \multicolumn{7}{|c|}{ BALANCE FISCAL GOBIERNO NACIONAL CENTRAL 2005-2010 (Miles de millones) } \\
\hline CONCEPTO & 2005 & 2006 & 2007 & 2008 & 2009 & 2010 \\
\hline $\begin{array}{l}\text { 1. INGRESOS } \\
\text { TOTALES (SIN } \\
\text { CAUSADOS) }\end{array}$ & $45.753,40$ & $56.287,10$ & $64.667,20$ & $75.041,90$ & $77.138,80$ & $74.940,20$ \\
\hline $\begin{array}{l}\text { INGRESOS } \\
\text { CORRIENTES DE } \\
\text { LA NACION }\end{array}$ & $42.517,90$ & $51.531,80$ & $58.249,00$ & $64.997,80$ & $65.659,00$ & $67.408,20$ \\
\hline $\begin{array}{l}\text { INGRESOS } \\
\text { TRIBUTARIOS }\end{array}$ & $42.288,40$ & $51.278,20$ & $57.866,00$ & $64.348,60$ & $65.196,00$ & $66.781,40$ \\
\hline $\begin{array}{l}\text { INGRESOS NO } \\
\text { TRIBUTARIOS }\end{array}$ & 229,5 & 253,6 & 383 & 649,3 & 463 & 626,9 \\
\hline
\end{tabular}




\section{Ramiro César Barajas Gómez}

Beneficios tributarios y su relación con el déficit fiscal en Colombia durante el período comprendido entre los años 2005 y 2010, artículo producto de la investigación

\begin{tabular}{|c|c|c|c|c|c|c|}
\hline \multicolumn{7}{|c|}{ BALANCE FISCAL GOBIERNO NACIONAL CENTRAL 2005-2010 (Miles de millones) } \\
\hline CONCEPTO & 2005 & 2006 & 2007 & 2008 & 2009 & 2010 \\
\hline $\begin{array}{l}\text { FONDOS } \\
\text { ESPECIALES }\end{array}$ & 471,9 & 577 & 637,1 & 894,4 & $1.061,50$ & $1.010,20$ \\
\hline $\begin{array}{l}\text { OTROS RECUR- } \\
\text { SOS DE CAPITAL }\end{array}$ & $2.763,70$ & $4.178,30$ & $5.781,00$ & $9.149,70$ & $10.418,30$ & $6.521,70$ \\
\hline $\begin{array}{l}\text { 2. PAGOS } \\
\text { TOTALES }\end{array}$ & $59.179,10$ & $67.558,40$ & $76.743,90$ & $83.704,90$ & $95.841,30$ & $93.708,30$ \\
\hline $\begin{array}{l}\text { PAGOS TOTALES } \\
\text { SIN INTERESES }\end{array}$ & $49.298,20$ & $54.231,10$ & $61.727,40$ & $69.781,80$ & $81.258,70$ & $79.495,60$ \\
\hline $\begin{array}{l}\text { PAGOS } \\
\text { CORRIENTES DE } \\
\text { LANACION }\end{array}$ & $54.806,60$ & $62.099,10$ & $68.427,40$ & $73.268,40$ & $84.503,40$ & $82.371,50$ \\
\hline INTERESES & $9.880,90$ & $13.327,30$ & $15.016,40$ & $13.923,20$ & $14.582,60$ & $14.212,70$ \\
\hline FUNCIONAMIENTO & $44.925,70$ & $48.771,80$ & $53.410,90$ & $59.345,20$ & $69.920,80$ & $68.158,80$ \\
\hline INVERSION & $4.372,50$ & $5.459,30$ & $8.316,50$ & $10.436,60$ & $11.337,80$ & $11.336,80$ \\
\hline $\begin{array}{l}\text { 3. DEFICIT O } \\
\text { SUPERAVIT } \\
\text { EFECTIVO }\end{array}$ & $-13.425,70$ & $-11.271,30$ & $-12.076,70$ & $-8.663,00$ & $-18.702,50$ & $-18.768,10$ \\
\hline $\begin{array}{l}\text { PRESTAMO } \\
\text { NETO }\end{array}$ & 323,9 & 412,2 & 257,1 & 166,2 & 176 & 214 \\
\hline $\begin{array}{l}\text { INGRESOS } \\
\text { CAUSADOS }\end{array}$ & 122,8 & 62,9 & 38,1 & 16,8 & 16,8 & 16,8 \\
\hline $\begin{array}{l}\text { GASTOS } \\
\text { CAUSADOS }\end{array}$ & 635,4 & 637,1 & 891,9 & $1.442,40$ & 566,5 & 634,3 \\
\hline $\begin{array}{l}\text { DEUDA } \\
\text { FLOTANTE }\end{array}$ & $-752,9$ & 810,9 & $-1.574,00$ & 812,9 & $1.286,80$ & $1.419,50$ \\
\hline $\begin{array}{l}\text { 4. DEFICIT O SU- } \\
\text { PERAVIT TOTAL }\end{array}$ & $-13.509,30$ & $-13.068,70$ & $-11.613,60$ & $-11.067,80$ & $-20.715,00$ & $-21.019,10$ \\
\hline $\begin{array}{l}\text { 5. COSTOS } \\
\text { DE LA REEST. } \\
\text { FINANCIERA }\end{array}$ & $1.233,20$ & $1.112,80$ & $1.160,70$ & $1.270,20$ & $1.117,30$ & 392,7 \\
\hline $\begin{array}{l}\text { 6. DEFICIT A } \\
\text { FINANCIAR }\end{array}$ & $-14.742,50$ & $-14.181,60$ & $-12.774,30$ & $-12.338,00$ & $-21.832,30$ & $-21.411,80$ \\
\hline $\begin{array}{l}\text { BALANCE } \\
\text { PRIMARIO }\end{array}$ & $-2.993,10$ & 895,7 & $4.294,70$ & $4.297,80$ & $-5.565,90$ & $-6.172,10$ \\
\hline
\end{tabular}

Aquí se hace necesario analizar un poco más la composición de los pagos para ver con claridad qué sucede con esta situación. En el año 2005 los pagos se componen de $\$ 9.88$ billones en pago de intereses $(16.7 \%)$, $\$ 44.9$ billones en gastos de funcionamiento $(75.9 \%)$ y $\$ 4.3$ billones en inversión $(7.3 \%)$. En 2010 la composición de los pagos totales del GNC están distribuidos así: $\$ 14.2$ billones en intereses (15.2\%), \$68.1 en funcionamiento $(72.7 \%)$ y $\$ 11.3$ 
billones en inversión (12\%). Nótese que el cambio en la distribución en los seis años analizados no es muy significativo, es decir, permanece más o menos constante. Claro, habría que ver la eficiencia y la eficacia de ese gasto, pero ello será objeto de otros estudios.

Lo más importante que muestran estos cuadros es la cuenta de déficit a financiar, el cual pasó de $\$ 14.7$ billones en 2005 a $\$ 21.4$ billones en solo seis años. Es decir, representó el $4.3 \%$ del PIB en 2005 , el $3.7 \%$ en 2006 , el $3.0 \%$ en $2007,2.6 \%$ en $2008,4.3 \%$ en 2009 y el $3.9 \%$ en 2010 . Significa que en términos relativos el incremento en el déficit no ha sido muy notorio, pero en términos absolutos sí es importante, ya que en comparación con los ingresos totales del GNC que representan en 2010 el 13.7\% del PIB, los pagos totales son un $17.1 \%$. El déficit de $3.9 \%$ del PIB es revelador de un problema al que el gobierno tendrá que dedicarle la atención justa. Es decir, aumentó en $42.6 \%$ entre 2005 y 2010: un total de $\$ 6.3$ billones.

\section{Financiación del déficit}

Ha sido tradicional en Colombia financiar el déficit con endeudamiento externo e interno y con el Impuesto al Valor Agregado (IVA), pues es éste último el mayor ingreso tributario con el argumento que si es adecuadamente diseñado, recauda más con menos costos administrativos y económicos que cualquier otro impuesto al consumo de base amplia. De todas maneras, tal como Restrepo (2009) dice, el «déficit de operaciones efectivas» (no incluye endeudamiento) -que es el que mide realmente el esfuerzo de financiamiento- se soluciona ya sea por operaciones de crédito, de nuevos impuestos, de reducción de gasto público, o de emisión, que se hace en un período determinado y que muestra la magnitud del ajuste. De la Tabla 12 se deduce que pasó de $-3.9 \%$ a $-3.4 \%$ entre 2005 y 2010 .

\section{Evasión}

Es claro que los ingresos del fisco han venido en aumento debido, muy seguramente, a la mayor actividad de la DIAN en el cobro de los impuestos y a la mejor conciencia tributaria de los contribuyentes. Sin embargo, la evasión en términos absolutos ha venido en aumento, así en la expresión porcentual aparezca con cierta reducción. Basta observar en la Tabla 13, para darse cuenta de la anterior afirmación. No es difícil entender cómo del recaudo potencial de IVA calculado por el DANE y la DIAN entre los años 2005 y 2010 , que viene aumentando de manera permanente, al igual que el recaudo, excepto en 2009 que por ser el dato preliminar puede aparecer con merma, es bien significativo. Empero, la evasión en IVA no permite duda en su constante incremento, que pasa de $\$ 8$ billones en 2005 a $\$ 10.6$ billones en la proyección para 2010; significando $2.4 \%$ del PIB en 2005 y $2.0 \%$ del PIB en 2010 (anotando, claro, que el PIB también se ha aumentado). 


\section{Ramiro César Barajas Gómez}

Beneficios tributarios y su relación con el déficit fiscal en Colombia durante el período comprendido entre los años 2005 y 2010, artículo producto de la investigación

Tabla 13. Estimación de la evasión en el impuesto al valor agregado 2005-2010pr.

\begin{tabular}{|c|c|c|c|c|c|c|}
\hline \multicolumn{7}{|c|}{$\begin{array}{l}\text { ESTIMACIÓN DE LA EVASIÓN EN EL IMPUESTO AL VALOR AGREGADO } \\
2005-2010 \mathrm{pr}\end{array}$} \\
\hline \multicolumn{7}{|c|}{ Miles de millones de pesos } \\
\hline & \multirow[t]{2}{*}{$\begin{array}{l}\text { RECAUDO } \\
\text { POTENCIAL(1) }\end{array}$} & \multirow[t]{2}{*}{$\begin{array}{l}\text { RECAUDO } \\
\text { BRUTO }\end{array}$} & \multirow[t]{2}{*}{ EVASIÓN } & \multirow[t]{2}{*}{$\begin{array}{l}\text { EVASIÓN/ } \\
\text { PIB }\end{array}$} & \multirow[t]{2}{*}{$\begin{array}{l}\text { TASA } \\
\text { EVASIÓN }\end{array}$} & \multirow[t]{2}{*}{$\begin{array}{l}\text { PUNTO } \\
\text { EVASIÓN }\end{array}$} \\
\hline AÑO & & & & & & \\
\hline 2005 & 26.468 & 18.462 & 8.006 & $2,4 \%$ & $30,2 \%$ & 265 \\
\hline 2006 & 31.415 & 22.698 & 8.717 & $2,3 \%$ & $27,7 \%$ & 314 \\
\hline 2007 & 34.775 & 26.151 & 8.624 & $2,0 \%$ & $24,8 \%$ & 348 \\
\hline 2008 & 37.451 & 28.571 & 8.880 & $1,9 \%$ & $23,7 \%$ & 375 \\
\hline $2009 p$ & 38.217 & 28.049 & 10.168 & $2,0 \%$ & $26,6 \%$ & 382 \\
\hline 2010pr & 41.976 & 31.362 & 10.614 & $2,0 \%$ & $25,3 \%$ & 420 \\
\hline \multicolumn{7}{|c|}{$\begin{array}{l}\text { (1):Al recaudo potencial se resta el IVA de las importaciones que según el Estatuto Tributario no } \\
\text { son gravadas, los } 2 \text { puntod de IVA por utilización de tarjetas débito o crédito, y para el año } \\
2010 \text { el IVA del mes de enero de verveza y juegos de suerte y azar que estaban a la tarifa del } 3 \% \text { y } \\
5 \% \text { respectivamente. }\end{array}$} \\
\hline \multicolumn{7}{|c|}{ Cálculos: Subdirección de Gestión de Análisis Operacional- DIAN } \\
\hline \multicolumn{7}{|c|}{ Fuente: MIP Nueva Base Cuentas Nacionales (Año 2005) DANE . } \\
\hline \multicolumn{7}{|c|}{ Modelo de Evasión en IVA - Subdirección de Gestión de Análisis Operacional - DIAN } \\
\hline Tomado & e Documentos we & 043 DIAN 20 & & & & \\
\hline
\end{tabular}

No es desconocido para los analistas que la tasa de evasión en IVA es alta. Sin embargo, la Tabla 13 revela verdades que todos conocen. En 2005 la tasa de evasión era de $30.2 \%$ frente a los ingresos tributarios y que ha disminuido en 2010 a $25.3 \%$, pero con una cifra para nada despreciable de $\$ 10.6$ billones y que significa un tránsito de \$265 mil millones por punto de evasión en 2005 a \$420 mil millones en 2010, lo cual muestra el tamaño del monto que deja de recibir el fisco nacional por incumplimiento de los contribuyentes. Por supuesto no son los consumidores los que evaden el IVA, sino quienes lo cobran y se quedan con él.

La evasión en impuesto de renta se calcula en 30\%, o sea, $\$ 11.6$ billones (El Espectador, 2010), lo cual aunado a la de IVA (10.6 billones) suman alrededor de $\$ 22.2$ billones en 2010. Esta suma, más las exenciones por $\$ 8$ billones, son $\$ 30.2$ billones, el cual es un monto muy considerable y asociado a las otras formas de evasión y elusión. Junto con los beneficios tributarios se podría, si se quisiera, solucionar el problema del déficit fiscal sin recurrir a endeudamiento o a mayores impuestos. 


\section{Conclusiones y recomendaciones}

Del anterior análisis se derivan algunas muy importantes conclusiones que permitirán a otros estudiosos profundizar en el tema de los beneficios tributarios y las soluciones al déficit fiscal.

Los beneficios tributarios, cualquiera que ellos sean, no han cumplido con los objetivos para los cuales han sido creados, tales como la atracción de inversión extranjera directa (IED), la generación de empleo e impulso al crecimiento y desarrollo económico, etc. Inclusive la IED, a la que se le han concedido muchos beneficios incluidos los contratos de estabilidad jurídica, tampoco ha cumplido con sus obligaciones y el gobierno no se las ha exigido. Basta con dar una mirada a las cifras de las zonas francas: en 2010, es decir, seis años después de comenzada la nueva etapa de beneficios tributarios, de los $\$ 12.2$ billones ofrecidos solo se ejecutó como nueva inversión con el $46.3 \%$; y de los 115.952 empleos ofrecidos, solo se cumplió con el $27.6 \%$.

Los beneficios tributarios, tal como afirma Galeano (2002), deben ser limitados en el tiempo para cada empresa o sector al que se le conceden y atados al cumplimiento de unas metas de rentabilidad superiores a las del mercado, para que no conviertan en subsidios a la mediocridad. Por tanto, los recursos son un premio a los mejores, nunca un subsidio a las malas empresas. Restrepo (2009) ayuda a soportar esta afirmación pues según él, como consecuencia de los cabildeos de los grupos de interés, los beneficios concedidos a estas empresas deben ser contrarrestados con más impuestos o endeudamiento. Según Carta Financiera (1998) se debe otorgar total neutralidad a las empresas sin otorgar ventajas que perjudiquen la competencia y la igualdad sin dar prerrogativas a competidor alguno. Esto, por supuesto, para que no se generen altas rentas a las empresas protegidas en detrimento de todos los consumidores (Kalmanovitz, 2010) y evitar que se cumpla la teoría del «public choice». Finalmente, no permitir que haya un tratamiento diferencial entre las empresas de la misma industria que estén dentro las zonas francas y fuera de ellas, porque se termina desestimulando la inversión y por supuesto la generación de empleo y el crecimiento y el desarrollo.

Será oportuno crear algunos impuestos para que los gobiernos locales tengan los recursos necesarios para sufragar sus gastos y subsanar su déficit. Estos impuestos serían, por ejemplo, la tributación a la propiedad de la tierra, ya que los cálculos que existen, permiten prever que con la sola actualización del catastro se generaría más del doble de los ingresos por concepto de impuesto predial (Kalmanovitz, 2010).

Crear impuestos a la minería, ya que los problemas de contaminación ambiental serán de gran magnitud y seguramente las regalías no solucionarán los problemas creados por las empresas mineras. 
Los aranceles que tienen su equivalente en la protección, deben otorgarse a aquellos bienes que requiere el mercado, pero que no compitan con los nacionales; y a las empresas que se les conceden los beneficios deben cumplir con su parte del trato. Un trato equilibrado para eliminar los privilegios puede ser el pago total de los impuestos correspondientes, más una importante multa si no se cumplen los compromisos adquiridos. Lo anterior debido a que en el caso colombiano, como afirma Kalmanovitz (2010) se otorgan subsidios sin contraparte, es decir, sin obligaciones reales por parte de las empresas favorecidas (lo cual «malcrió» a los empresarios y hace que se presente competencia desleal, pues es sabido que, por ejemplo, el $70 \%$ del empleo en Colombia lo generan las Mipymes y éstas carecen de incentivos). Stigliz (1995) dice que en Estados Unidos las empresas que reciben algún incentivo deben corresponder a él con el cumplimiento de obligaciones precisas. Por tanto, se hace necesario darle al gobierno las herramientas necesarias para que pueda cobrar los beneficios otorgados a las empresas que no cumplan y las pueda sancionar y crear verdaderos mecanismo de verificación y monitoreo para que no se presenten evasión y elusión-de tal manera que sean transparentes y que no se concedan de manera discrecional.

Las exenciones que los municipios están ofreciendo a las empresas para que establezcan en su territorio con el fin de crear empleo, deben eliminarse, o cuando menos verificarse si se cumplen los objetivos. Y es necesario ya que lo que generalmente ocurre es que el municipio termina sufragando gastos adicionales en vivienda, servicios públicos etc., puesto que llegan más personas a trabajar que los empleos que se ofrecieron a los nativos.

Frenar la concesión de licencias de zonas francas y redefinir los requerimientos de acuerdo con claros objetivos, hasta tanto las ya existentes demuestren que han cumplido con su parte y establecer castigos pecuniarios por el incumplimiento.

Establecer como delito penal no solo la evasión, sino todas las infracciones cometidas contra el Fisco y endurecer las penas contra el contrabando y el lavado de activos. Como afirma Perry (1992), uno de los temas más polémicos es el de la ampliación de los casos de defraudación al fisco que constituyen un delito penal. Y afirma que allá se habrá de llegar algún día si se quiere modernizar el país. Expresa además que los países industrializados consideran la defraudación fiscal como delito penal y se castiga como tal. En el mismo sentido se expresa Piza (1992), y asevera que la evasión además de ser un delito que atenta contra toda la sociedad, altera la equidad del sistema tributario porque las cargas se reparten de manera desigual entre los contribuyentes. Este autor plantea como estrategia para mejorar la 
equidad tributaria la creación de la figura de defraudación fiscal para que vayan a la cárcel aquellos que evaden impuestos.

Eliminar las exenciones a los salarios de los altos funcionarios del Estado en aras de la equidad tributaria, plasmadas en el inciso 3 del numeral 7 del artículo 206 del Estatuto Tributario y en Sentencia C-748 de 2009.

Los contratos de estabilidad jurídica deben obedecer a una política nacional, y no al capricho de un funcionario. Pues tal como lo afirman Perry (2010), Steiner (2010) y Ávila (2010), estos son una inequidad dramática que afecta los recaudos totales y se está creando un Frankenstein que creainestabilidad al garantizar a los inversionistas la aplicación de norma anteriores por largos períodos, generando rigideces al sistema e impidiendo una reforma integral de requerirse. En la mayoría de estos contratos las empresas estabilizaron las ventajas concebidas por exenciones y deducciones especiales a las empresas respectivas, y en muchos casos, concedidas a sus accionistas, presentando desigualdad en empresas similares que tienen tratamiento tributario distinto y que son difíciles de desmontar por ser derechos adquiridos.

Sin importar que sea necesaria una reforma al sistema monetario internacional, se debe ir pensando seriamente en la propuesta del economista francés Maurice Allais, Premio Nobel de 1988, sobre la necesidad de la desaparición de los impuestos directos (renta y sucesiones) y el reemplazo por un impuesto sobre los activos fijos, trasladando los recursos generados por la emisión secundaria de dinero al gobierno y gravando todos los bienes de consumo con una tasa uniforme, no progresiva, con lo cual solucionaría en buena parte su necesidad de fondos.

Para nada es despreciable la propuesta de Javier Ávila (2010), en el sentido de bajar la tasa del impuesto renta al $25 \%$ si se eliminan exenciones y combate la evasión, es decir, el $25 \%$ para todos sin beneficios y hacerla inmediatamente aunque duela.

Es claro que no solo disminuyendo gasto público, aumentando los impuestos de renta e IVA y el crédito se puede solucionar el déficit fiscal. Hay otros mecanismos más expeditos y convenientes para hacerlo, tales como eliminar beneficios tributarios, elevar a delito penal la evasión para acabarla, impedir la elusión y la corrupción con normas claras y contundentes. Pues tan solo con sumar los beneficios tributarios en renta (incluidas las zonas francas) de alrededor de $\$ 7$ billones, la evasión en IVA de $\$ 21$ billones y renta $\$ 11.6$ billones, es un monto muy considerable que si se quisiera, solucionaría el problema del déficit fiscal sin recurrir 


\section{Ramiro César Barajas Gómez}

Beneficios tributarios y su relación con el déficit fiscal en Colombia durante el período comprendido entre los años 2005 y 2010, artículo producto de la investigación

al endeudamiento o a mayores impuestos. Lo racional sería que si se elige pagar el gasto público con endeudamiento, la misma economía debe generar suficientes ingresos para sufragarlos, sin necesidad de cambiar los tipos ni imponer nuevos tributos, pues los sectores beneficiados deben haber generado suficientes ingresos para pagarlos incluido el servicio de la deuda. Es decir, entre una y otra forma de financiación, solo hay tiempo de por medio y generación de mayores utilidades, o de lo contrario no vale pena incrementar el gasto.

\section{Referencias bibliográfícas}

Ávila, J. 2010. Foro sobre Reforma Tributaria en Colombia. Celebrado en la Universidad Jorge Tadeo Lozano, el 9 de Octubre de 2010.

ANIF. 1998. «La Corte ataca privilegios tributarios indebidos». Carta financiera. 108:---.

Bonilla-Castro, E. y P. Rodríguez. 1997. Más allá del dilema de los métodos: la investigación en ciencias sociales. Bogotá: Uniandes-Norma.

DANE. «Económicos y cuentas nacionales». Tomado el --- de Dane.gov.co.

DIAN. Coordinación de estudios económicos y Subdirección de análisis operacional. Dian.gov.co.

«---»El Espectador.10 de mayo de 2009. Tomado el --- de ---

«---» El Espectador. 22 de noviembre de 2010. Tomado el --- de ---

Galeano, N. et al. 2002. «De promover exportaciones a promover la competitividad global: instrumentos del siglo XX adaptados al siglo XXI». Economía colombiana. 289: 43-49.

Hernández Sampieri, R. et al. 2005. Metodología de la investigación. México D.F.: McGraw-Hill.

Kalmanovitz, S. (Ed.) 2010. Nueva historia económica de Colombia. Bogotá: Taurus.

Mincomercio. 2009. Manual para presentación de solicitudes de declaratoria de zonas francas. Bogotá: Fiducoldex.

Ministerio de Hacienda. Centro de estudios fiscales. Minhacienda.gov.co.

Parra, G. et al. 2011. El gasto tributario en Colombia. Principales beneficios en el impuesto sobre la renta e IVA. Años gravables 2008 y 2009 [versión electrónica]. Tomado --- de 
http://www.dian.gov.co/descargas/Servicios/OEE-Documentos/Cuadernos/Gasto_ tributario_2010_19112010.pdf

Perry, G. 1992. «---». Debates de coyuntura económica. 24: ---.

Piza, J. 1992. «---». Debates de coyuntura económica. 24.

Ramos, J. y K. Rodríguez. 2011. «Zonas Francas en Colombia: beneficios tributarios en el impuesto de renta». Borradores de economía. 657: 1-19.

Restrepo, J. C. 2009. Hacienda Pública. Bogotá: Universidad Externado de Colombia.

Steiner, R. 2010. Foro sobre Reforma Tributaria en Colombia. Celebrado en la Universidad Jorge Tadeo Lozano, el 9 de Octubre de 2010.

Stiglitz, J. 1995. Economía del Sector Público. Barcelona: Antoni Bosch.

Todaro, M. P. 1985. Desarrollo económico del tercer mundo. Madrid: Editorial Alianza Universitaria.

Legislación consultada:

Ley 1004 de 2005

Decretos 383 de 2007

Decreto 4041 de 2007 